\title{
OPTIMISING THE ANALYSIS STAGE IN THE INTERNATIONALISATION OF MANUFACTURING OPERATIONS
}

\author{
F. Comer ${ }^{1}$, J. Mula ${ }^{1 *}$, M. Díaz-Madroñero ${ }^{1} \&$ H. Grillo ${ }^{2}$
}

\section{ARTICLE INFO}

Article details

Submitted by authors 2 Nov 2020

Accepted for publication 18 Jan 2021

Available online $\quad 31$ Aug 2021

Contact details

Corresponding author

fmula@cigip.upv.es

Author affiliations

1 Research Centre on Production Management and Engineering

(CIGIP), Universitat Politècnica de València, C/ Alarcón, 1, 03801, Alcoy, Alicante, Spain

2 Industrial Engineering School, University of Costa Rica: San José, Costa Rica

\section{ORCID® identifiers}

F.Comer

https: / /orcid.org/0000-0002-0595-5311

J. Mula

http://orcid.org/0000-0002-8447-3387

M. Díaz-Madroñero

http: / / orcid.org/0000-0003-1693-2876

H. Grillo

http://orcid.org/0000-0001-8621-930X

DOI

http: / /dx.doi.org/10.7166/32-2-2371

\section{ABSTRACT}

The internationalisation of the manufacturing operations process includes decision-making about new facility implementation (NFI) and global supplier network development (GSND), whose first step is to analyse the situation of a company and its environment. The purpose of this paper is to investigate the optimal design of a manufacturing production and distribution network for global small- and medium-sized enterprises (SMEs). This research uses a mixed-integer linear programming (MILP) model to support decision-making in the analysis stage of the internationalisation of manufacturing operations for global SMEs. A realworld case study is presented to illustrate the application of the proposed model. Different scenarios were evaluated not only to identify the strengths and limitations of the mathematical programming model, but to also provide support for the next strategic decisions that the examined company has to make in the near future.

\section{OPSOMMING}

Die besluit om nuwe vervaardigingsfasiliteite op te rig en die ontwikkeling van wêreldwye verskaffernetwerke is belangrik vir die internasionalisering van operasionele prosesse in vervaarding. Die eerste stap van hierdie ontwikkeling is die ontleding van die maatskappy se omstandighede. Die doel van hierdie studie is om die optimale ontwerp van ' $n$ vervaardiging produksie- en verspreidingsnetwerk te ondersoek vir klein en medium grootte ondernemings. Die navorsing gebruik' $n$ gemengde heelgetal lineêre programmeringsmodel om besluitneming te ondersteun tydens die aanvanklike ontledings fase. 'n Gevallestudie van 'n werklike maatskappy word voorgehou om die toepassing van die voorgestelde model te illustreer. Verskillende scenario's is ontleed en identifiseer nie net die voor- en nadele van die model nie; dit bied ook ondersteuning vir die volgende strategiese besluite wat die maatskappy moet neem in die nabye toekoms.

\section{INTRODUCTION}

The need for international markets to develop with more diverse and sophisticated customer requirements, and to put into practice global operations strategies (e.g., offshoring and backshoring) means having to shape and manage increasingly complex networks for production and logistics [1, 2, 3, 4]. Thus fragmenting production processes and the multilocalisation of activities have become more relevant [5]. In general terms, a company's production and logistics system design has to fall in line with its internationalisation business strategy [6]. To this end, it is necessary to make production and logistics decisions by managing resources and developing competencies to meet market requirements. The critical decisions made when designing and outlining a global supply chain are: the location of supply sources (own and otherwise); the strategic role of plants, suppliers and warehouses; the integration or fragmentation of production and logistic operations (decisions to produce or purchase); service delivery strategies (supply strategy, manufacturing strategy, purchases strategy); and a global operations network (distribution network, manufacturing network, supplier network). These production and logistics strategies require configuring a model with production multilocalisation and/or distributed production, and organising direct and inverse logistics flows $[7,8]$. However, the processes and practice followed to improve and optimise production network performance have not been sufficiently analysed [9], especially when it comes to dealing with new 
production implementations and constantly reconfiguring and/or adapting international manufacturing networks $[10,11]$. Hence it is necessary to develop a new analytical frame to: introduce the distributed production concept, or multilocalisation, into supply chain design models; cover several objectives simultaneously by jointly considering production and logistics decisions; incorporate tools into the analysis and design phase that allow the robustness and security concepts of analysis and design to be included in reconfigured supply chains and production plants [12]; and provide new comprehensive mathematical models that can effectively help managers to make suitable decisions on the internationalisation of operations. It is worth stressing that, when an industrial company wishes to open a plant in a new geographic region - i.e., new facility implementation (NFI) - or when it wishes to develop a global supplier network development (GSND), it must consider the following five stages [13]: analysis, setup, stability, improvement, and excellence. For a literature review on the internationalisation of manufacturing operations, we refer readers to [14, 15, 16, 17]. In this sense, Armengol et al. [18] identify a research gap on quantitative tools for decision-making on the internationalisation of operations. Here, this work focuses on a specific analysis stage that requires configuring a decision model to deal with NFI and GSND challenges [13] that impact the production and logistics system design, as well as the associated suppliers network design [19, 20]. The main contributions of the paper are twofold: (i) to propose a new mixed integer linear programming (MILP) model with production multilocalisation and distributed production to optimise and simulate the analysis and design of global supply chains; and (ii) to test and validate the proposed model in a real case study of a Spanish SME (small and medium enterprise) manufacturing office chairs.

The remainder of this article is arranged as follows. Section 2 describes the formulation of a MILP model for NFI and GSND configuration. Section 3 validates and evaluates the proposed model in a real-world application. Section 4 offers the main conclusions and suggestions for further research.

\section{MODEL FORMULATION}

Modelling is based on MILP with its elements, constraints, and objective function. The goal we intend to meet with this model is to determine the total profit by bearing in mind all the production plants. Thus the objective function, which includes the sales, replenishment costs, and production costs of the national, foreign, and new plants, is maximised, and is subject to a series of related economic and technical constraints.

\subsection{Objective function}

The income that comes from all the plants, based on the amount produced and the equivalent unit sale price, is as follows.

Total input from foreign plants:

$$
T F I=\sum_{j \in F O(j)} \sum_{u \in U} \sum_{k \in K} \sum_{t} s p_{u j} Q U_{u j k t}
$$

Total input from new plants:

$$
I N F I=\sum_{j \in N I(j)} \sum_{u \in U} \sum_{k \in K} \sum_{t} s p_{u j} Q U_{u j k t}
$$

Total inputs from national plants:

$$
T N I=\sum_{j \in N A(j)} \sum_{u \in U} \sum_{k \in K} \sum_{t} s p_{u j} Q U_{u j k t}
$$

The supply costs are provided below.

The supply cost for national plants from foreign suppliers:

$$
T F S C n i=\sum_{i \in F O(i)} \sum_{j \in N A(j)} \sum_{r \in R} \sum_{t}\left(\operatorname{csup}_{r i}+t c r_{r i j}\right) Q R_{r i j t}
$$


The supply cost for national plants from national suppliers:

$$
T N S C n i=\sum_{i \in N A(i)} \sum_{j \in N A(j)} \sum_{r \in R} \sum_{t}\left(\operatorname{csup}_{r i}+t c r_{r i j}\right) Q R_{r i j t}
$$

The supply cost for foreign plants from foreign suppliers:

$$
T F S C f i=\sum_{i \in F O(i)} \sum_{j \in F O(j)} \sum_{r \in R} \sum_{t}\left(\operatorname{csup}_{r i}+t c r_{r i j}\right) Q R_{r i j t}
$$

The supply cost for foreign plants from national suppliers:

$$
T N S C f i=\sum_{i \in N A(i)} \sum_{j \in F O(j)} \sum_{r \in R} \sum_{t}\left(\operatorname{csup}_{r i}+t c r_{r i j}\right) Q R_{r i j t}
$$

The supply cost for new plants from foreign suppliers:

$$
\text { TFSCnfi }=\sum_{i \in F O(i)} \sum_{j \in N I(j)} \sum_{r \in R} \sum_{t}\left(\operatorname{csup}_{r i}+t c r_{r i j}\right) Q R_{r i j t}
$$

The supply cost for new plants from national suppliers:

$$
T N S C n f i=\sum_{i \in N A(i)} \sum_{j \in N I(j)} \sum_{r \in R} \sum_{t}\left(\operatorname{csup}_{r i}+t c r_{r i j}\right) Q R_{r i j t}
$$

The contemplated production costs are as follows:

The total production cost from foreign plants:

$$
\begin{gathered}
T F P C=\sum_{j \in F O(j)} \sum_{r \in R} \sum_{t} i h c r_{r j} S T R_{r j t}+\sum_{j \in F O(j)} \sum_{u \in U} \sum_{t} i h c u_{u j} S T U_{u j t}+ \\
+\sum_{j \in F O(j)} \sum_{u \in U} \sum_{t}\left(p c_{u j}+p r d c_{u j}\right) Q_{u j t}+\sum_{j \in F O(j)} \sum_{t} c h f_{j} r o t_{j} H M_{j t}+ \\
+\sum_{j \in F O(j)} \sum_{t}\left(c s p_{j}+t e c h_{j}\right) B S_{j t}+\sum_{j \in F O(j)} \sum_{u \in U} \sum_{k \in K} \sum_{t} t c u_{u j k} Q U_{u j k t}
\end{gathered}
$$

The total production cost from new plants:

$$
\begin{gathered}
\text { PCNFI }=\sum_{j \in N I(j)} \sum_{r \in R} \sum_{t} i h c r_{r j} S T R_{r j t}+\sum_{j \in N I(j)} \sum_{u \in U} \sum_{t} i h c u_{u j} S T U_{u j t}+ \\
+\sum_{j \in N I(j)} \sum_{u \in U} \sum_{t}\left(p c_{u j}+p r d c_{u j}\right) Q_{u j t}+\sum_{j \in N I(j)} \sum_{t}^{t} c h f_{j} r o t_{j} H M_{j t}+ \\
+\sum_{j \in N I(j)} \sum_{t}\left(c s p_{j}+t e c h_{j}\right) B S_{j t}+\sum_{j \in N I(j)} \sum_{u \in U} \sum_{k \in K} \sum_{t} t c u_{u j k} Q U_{u j k t}
\end{gathered}
$$

The total production cost from national plants:

$$
\begin{gathered}
\text { TNPC }=\sum_{j \in N A(j)} \sum_{r \in R} \sum_{t} i h c r_{r j} S T R_{r j t}+\sum_{j \in N A(j)} \sum_{u \in U} \sum_{t} i h c u_{u j} S T U_{u j t}+ \\
+\sum_{j \in N A(j)} \sum_{u \in U} \sum_{t}\left(p c_{u j}+p r d c_{u j}\right) Q_{u j t}+\sum_{j \in N A(j)} \sum_{t} c h f_{j} r o t_{j} H M_{j t}+ \\
+\sum_{j \in N A(j)} \sum_{t}\left(c s p_{j}+t e c h_{j}\right) B S_{j t}+\sum_{j \in N A(j)} \sum_{u \in U} \sum_{k \in K} \sum_{t} t c u_{u j k} Q U_{u j k t}
\end{gathered}
$$


Based on the income and the previously identified costs, the total profit will be:

The total profit of foreign plants:

$$
\text { TotForeignProf }=\text { TFI }- \text { TFSCfi }- \text { TNSCfi }- \text { TFPC }
$$

The total profit of new plants:

$$
\text { ProfNewFacility }=I N F I-T F S C n f i-T N S C n f i-P C N F I
$$

The total profit of national plants:

$$
\text { TotNatProf }=\text { TNI }- \text { TFSCni }- \text { TNSCni }- \text { TNPC }
$$

The total profit:

$$
\text { TotProf }=\text { TotForeignProf }+ \text { ProfNewFacility }+ \text { TotNatProf }
$$

The equation below shows the objective function to be maximised:

$$
f=\max (\text { TotProf })
$$

\begin{tabular}{|c|c|}
\hline \multicolumn{2}{|c|}{ Set of indices } \\
\hline$U$ & Set of the equivalent finished product units from plant $j$ to customer $k(u=1, \ldots, U)$ \\
\hline$R$ & Set of the equivalent raw material units from supplier $i$ to plant $j(r=1, \ldots, R)$ \\
\hline$I$ & Set of suppliers $(i=1, \ldots, l)$ \\
\hline$J$ & Set of production plants $(j=1, \ldots, J)$ \\
\hline$K$ & Set of customers $(k=1, \ldots, K)$ \\
\hline$T$ & Set of time periods in the time horizon $(t=1, \ldots, T)$ \\
\hline \multicolumn{2}{|c|}{ Sub-sets of indices } \\
\hline$F O(i)$ & Set of foreign suppliers \\
\hline$N A(i)$ & Set of national suppliers \\
\hline$F O(j)$ & Set of foreign production plants \\
\hline$N A(j)$ & Set of national production plants \\
\hline$N I(j)$ & Set of new production plants \\
\hline \multicolumn{2}{|c|}{ Model parameters } \\
\hline csup & Cost of purchasing an equivalent unit of raw material $r$ from supplier $i$ \\
\hline$i h c r_{r j}$ & Cost of maintaining the inventory of an equivalent unit of raw material $r$ in production plant $j$ \\
\hline$i h c u_{u j}$ & Cost of maintaining the inventory of an equivalent unit of finished product $u$ in production plant $j$ \\
\hline maxihr $_{r j}$ & Maximum inventory of an equivalent unit of raw material $r$ allowed in production plant $j$ \\
\hline $\operatorname{maxihu}_{u j}$ & Maximum inventory of an equivalent unit of finished product $u$ allowed in production plant $j$ \\
\hline$p C_{u j}$ & Cost of the personnel required per equivalent unit of finished product $u$ in production plant $j$ \\
\hline$s p_{u j}$ & Sale price of an equivalent unit of finished product $u$ in production plant $j$ \\
\hline$p t_{u j}$ & Time required to produce an equivalent unit of finished product $u$ in production plant $j$ \\
\hline $\operatorname{prdc}_{u j}$ & $\begin{array}{l}\text { The production cost (the general costs attributed to the product, apart from the raw material and labour } \\
\text { costs) of an equivalent unit of finished product } u \text { in production plant } j\end{array}$ \\
\hline$t c r_{r i j}$ & Cost of transporting an equivalent unit of raw material $r$ from supplier $i$ to production plant $j$ \\
\hline$t c u_{u j k}$ & Cost of transporting an equivalent unit of finished product $u$ from production plant $j$ to customer $k$ \\
\hline rqukt & Quantity required of an equivalent unit of finished product $u$ from customer $k$ during time period $t$ \\
\hline$n_{r u}$ & $\begin{array}{l}\text { Average quantity of an equivalent unit of raw material } r \text { required to produce an equivalent unit of finished } \\
\text { product } u\end{array}$ \\
\hline$h_{u m}$ & $\begin{array}{l}\text { Ratio of the average staff required for an equivalent unit of finished product } u \text { produced in production } \\
\text { plant } j\end{array}$ \\
\hline $\operatorname{rot}_{j}$ & The average staff turnover index in production plant $j$ \\
\hline$c h f_{j}$ & The average contracting-dismissal costs on production plant $j$ \\
\hline $\operatorname{capmax}_{j}$ & Maximum capacity (expressed in hours) per production plant $j$ \\
\hline$s p C_{u}$ & $\begin{array}{l}\text { Ratio of the average space (area in } \mathrm{m}^{2} \text { ) built per equivalent unit of finished product } u \text { produced in } \\
\text { production plants }\end{array}$ \\
\hline $\operatorname{csp}_{j}$ & The average construction cost per $\mathrm{m}^{2}$ of production plant $j$ \\
\hline
\end{tabular}

Table 1 provides the nomenclature of the proposed MILP model for the analysis stage on the internationalisation of manufacturing operations.

\section{Table 1: Nomenclature}




\begin{tabular}{|l|l|}
\hline$t e c h_{j}$ & The average technological maintenance cost per $\mathrm{m}^{2}$ of production plant $j$ \\
\hline$s t u O_{u j}$ & The initial finished product stock $(t=0)$ \\
\hline$s t r 0_{r j}$ & The initial raw material stock $(t=0)$ \\
\hline Decision variables \\
\hline$Q R_{r i j t}$ & $\begin{array}{l}\text { The total quantity of an equivalent unit of raw material } r \text { to be sent from supplier } i \text { to production plant } \\
j \text { during time period } t\end{array}$ \\
\hline$Q_{u j t}$ & $\begin{array}{l}\text { The total quantity of an equivalent unit of finished product } u \text { to be produced in production plant } j \text { during } \\
\text { time period } t\end{array}$ \\
\hline$Q U_{u j k t}$ & $\begin{array}{l}\text { The total quantity of an equivalent unit of finished product } u \text { to be sent from production plant } j \text { to } \\
\text { customer } k \text { during time period } t\end{array}$ \\
\hline$S T U_{u j t}$ & Stock of an equivalent unit of finished product $u$ in production plant $j$ during time period $t$ \\
\hline$S T R_{r j t}$ & Stock of an equivalent unit of raw material $r$ in production plant $j$ during time period $t$ \\
\hline$C A P_{j t}$ & Total required capacity (in hours) in production plant $j$ during time period $t$ \\
\hline$B S_{j t}$ & Total required constructed space (in m ${ }^{2}$ ) per production plant $j$ during time period $t$ \\
\hline$H M_{j t}$ & Total required staff per production plant $j$ during time period $t$ \\
\hline
\end{tabular}

\subsection{Constraints}

The following constraints were considered, based on the inventory balance, capacity/space requirements, and staff requirements. The constraint defined by equation (18) indicates that the stock of an equivalent unit of finished product in production plant $j$ at the end of the first period equals the initial inventory, plus the quality to be produced, minus the total requirement to be sent to the set of customers. Similarly, equation (19) allows the stock for $u$ to be calculated for the time periods following the first ones. Moreover, the stock in question cannot exceed the maximum inventory of the equivalent unit of finished product allowed in this production plant (20). Equation (21) indicates that customers' demand equals the total quantity of the equivalent unit of finished product $u$ to be sent to customers during period $t$ from the set of production plants. Equation (22) determines the stock of this quantity of raw material $r$ in production plant $j$ at the end of the first period, while equation (23) is for the time periods that follow. Finally, equation (24) guarantees that the stock of an equivalent unit of raw material does not exceed the maximum inventory allowed. For the capacity and space requirements, equation (25) indicates that the total capacity required in production plant $j$ depends on the time needed to produce an equivalent unit of finished product and the total quantity to be produced. Moreover, this total capacity cannot exceed the maximum capacity per production plant (26). The total constructed space required per production plant depends on the average space ratio constructed per equivalent unit of finished product produced in the plant and the total quantity that needs to be produced (27). The total staff required per production plant depends on the ratio of the average staff required for an equivalent unit of finished product made in the plant and the total quantity that needs to be produced (28). We conclude by indicating the non-negativity and the integrality of the decision variables (29).

$$
\begin{gathered}
S T U_{u j t}=s t u 0_{u j}+Q_{u j t}-\sum_{k} Q U_{u j k t} \forall u \in U, j \in J, t=1 \\
S T U_{u j t}=S T U_{u j, t-1}+Q_{u j t}-\sum_{k} Q U_{u j k t} \forall u \in U, j \in J, t>1 \\
S T U_{u j t} \leq \operatorname{maxihu}_{u j} \forall u \in U, j \in J, t \\
r q_{u k t}=\sum_{j} Q U_{u j k t} \forall u \in U, k \in K, t \\
S T R_{r j t}=s t r 0_{r j+} \sum_{i} Q R_{r i j t}-\sum_{u} n_{r u} Q_{u j t} \forall r \in R, j \in J, t=1 \\
S T R_{r j t}=S T R_{r j, t-1+} \sum_{i} Q R_{r i j t}-\sum_{u} n_{r u} Q_{u j t} \forall r \in R, j \in J, t>1 \\
S T R_{r j t} \leq \operatorname{maxihr}_{r j} \forall r \in R, j \in J, t \\
C A P_{j t}=\sum_{u} p t_{u j} Q_{u j t} \forall j \in J, t \\
C A P_{j t} \leq c a p m a x x_{j} \forall j \in J, t \\
B S_{j t}=\sum_{u} s p c_{u} Q_{u j t} \forall j \in J, t \\
H M_{j t}=\sum_{u} h u m_{u j} Q_{u j t} \forall j \in J, t
\end{gathered}
$$




$$
\begin{gathered}
Q R_{\text {rijt },} Q_{u j t,} Q U_{u j k t,} S T U_{u j t,} S T R_{r j t,} C A P_{j t}, B S_{j t}, H M_{j t} \geq 0 \text { and } \\
Q_{u j t,} Q U_{u j k t}, S T U_{u j t} \in \mathbb{Z} \forall u \in U, r \in R, i \in I, j \in J, t \in T
\end{gathered}
$$

3

\section{APPLICATION}

In order to test and validate the proposed model in an application based on real data, we opted to study the case of a Spanish SME that manufactures office chairs according to a make-to-order manufacturing strategy. The production process phases are summarised in the following main stages: cutting, sewing, pasting, upholstering, and final assembly. In the context of the internationalisation of manufacturing operations, the company has recently opened a production plant in Cuba, thanks also to a global supplier network. After this initial internationalisation phase of operations, the next challenge is represented by a possible NFI in Miami, a strategic point to cover the North American market according to forecasted demand. To represent it, the following were considered: three end products, $u$; 15 raw materials, $r ; 10$ suppliers, $i$; three production plants (national, international, and an international NFI); and five global customers. The considered planning horizon included two different trimesters or time periods. The input data details can be found by clicking on the following link: https://bit.ly/2sioJVt

\subsection{Implementation and resolution}

The proposed mathematical model was implemented in version 4.2 of the MPL modelling language. Resolution was carried out with the optimisation solver CPLEX 12.1.0. The experiment was run using an Intel ${ }^{\circledR}$ Core $^{\mathrm{TM} 2}$ Duo CPU processor of $2.20 \mathrm{GHz}$ and $4 \mathrm{~GB}$ RAM. This MILP model was developed after considering three different scenarios. The first one (case A) indicated no limitation for exports from any production plant, and in particular exporting from Cuba to any country is permitted. The second scenario (case B) considers the possibility of blocking exports from the Cuban plant to the customer located in Miami. The third scenario (case $\mathrm{C}$ ) contemplates the hypothesis of banning all exports from the Caribbean country to stress the global impact that not being able to sell from a plant may have.

\subsection{Evaluation of the results}

Case A (exports allowed from Cuba to any country) contemplates no limitation on exports from the Cuban plant. Its effects are visible in the results: high income in all the plants, with the highest income in the Cuban plant; similar costs between the national plant and that located in Miami (where the most relevant costs are related to construction and technological maintenance), with very low costs in the Cuban plant (where transport costs, $t c u_{u j k}$, prevail). All this implies high profits in the Cuban plant. Compared with the other plants, the reason for the high profits made in the Cuban plant is the following. Apart from replenishments costs, which are higher owing to more components being required for manufacturing purposes, production costs are much lower, particularly personnel costs, construction costs, and technological maintenance costs. Moreover, the MILP model favours the production and sale of the finished products from Cuba owing not only to savings in costs, but also to higher sale prices being applied than in the other production plants. The total profit made is $€ 366,718.17$. In case $B$ (exports not allowed from Cuba to the USA), exports from branch $j=2$ to $k=1$ are not allowed - i.e., between the Cuban plant and the customer in Miami. In terms of global income, costs, and profits, the considerations made for case A are the same for case B, with the only difference being that the income lost by the Cuban plant, because of the restriction in question, has been transferred to the Miami plant. For this reason, and bearing in mind that production costs are higher in Miami and sale prices are lower than the production and sales from Cuba, the profit in Miami increased, it decreased in Cuba, and the total profit slightly decreased by $€$ $1,564,41$ compared with case A. Table 2 presents a comparison of case $A$ and case $B$ that shows: a situation of invariability for the national plant; loss of income and profit for the Cuban plant, as costs do not significantly vary; an increase in the income for the Miami plant, which absorbs the sales of branch $j=2$ to $k=1$, and whose profits increase by $18.37 \%$; a general loss in total profit of $0.43 \%$ because producing units of finished products in Miami instead of Cuba entails higher production costs on the one hand, and lower sale prices on the other hand.

Finally, let's look at case $C$, which does not allow any exports from the Cuban plant. It is noteworthy that case B in today's context represents a more realistic situation than case A, which assumes a more optimistic situation than case $\mathrm{C}$, which is more pessimistic. For this plant in particular, the proposed limitation has the following effects: as it cannot sell, it makes no income; as it cannot sell, it does not manufacture and, therefore, it does not need replenishing (no replenishment costs); as it cannot sell, it does not manufacture and, therefore, production costs do not exist. The only remaining cost stems from the initial stock of components for manufacturing, which are stored. Therefore the plant's profit only equals these last costs from storing raw material. As the Cuban plant does not operate, it corresponds to an increase not only of 
income, but also of the replenishment and production costs in the other two plants, which consequently increase the profits of both, particularly for the national plant, whose profits more than double. The fact that the Cuban plant 'disappears' means that it was necessary to increase the staff and productivity in the other two plants: the national plant benefits from these increases for equivalent product units $u=1$ and $u=3$, while the plant in Miami only does so for $u=2$. This explains the rise in both income and profits, especially in the Spanish plant (Table 3). The expected total profit is $€ 246,721.87$.

Table 2: Comparison of case B and case A

\begin{tabular}{|l|l|l|l|l|l|}
\hline \multicolumn{2}{|l|}{ Foreign plant } & NFI & National plant & \\
\hline Objective function component & $+/-\%$ & Objective function component & $+/-\%$ & Objective function component & $+/-\%$ \\
\hline TFI & -5.41 & INFI & 6.18 & TNI & 0.02 \\
\hline TFSCfi & -3.69 & TFSCnfi & -1.24 & TFSCni & 0.01 \\
\hline TNSCfi & 0.00 & TNSCnfi & 0.00 & TNSCni & 0.00 \\
\hline TFPCa & 0.00 & PCNFIa & -25.57 & TNPCa & 0.00 \\
\hline TFPCb & 0.00 & PCNFIb & 0.00 & TNPCb & 0.00 \\
\hline TFPCC & -0.62 & PCNFIc & 1.74 & TNPCc & 0.01 \\
\hline TFPCd & 0.01 & PCNFId & 5.10 & TNPCd & 0.00 \\
\hline TFPCe & 0.82 & PCNFle & -0.76 & TNPCe & 0.00 \\
\hline TFPCf & 1.75 & PCNFIf & -5.41 & TNPCf & -0.21 \\
\hline TotForeignProf & -6.52 & ProfNewFacility & 18.37 & TotNatProf & 0.06 \\
\hline TotProf & -0.43 & \multicolumn{4}{|l}{} \\
\hline
\end{tabular}

Table 3: Comparison of case $\mathrm{C}$ and case $\mathrm{A}$

\begin{tabular}{|c|c|c|c|c|c|}
\hline \multicolumn{2}{|l|}{ Foreign plant } & \multicolumn{2}{|l|}{$\mathrm{NFI}$} & \multicolumn{2}{|l|}{ National plant } \\
\hline $\begin{array}{l}\text { Objective function } \\
\text { component }\end{array}$ & $+/-\%$ & $\begin{array}{l}\text { Objective function } \\
\text { component }\end{array}$ & $+/-\%$ & $\begin{array}{ll}\text { Objective } & \text { function } \\
\text { component } & \end{array}$ & $+/-\%$ \\
\hline TFI & -100.00 & INFI & 24.10 & $T N I$ & 80.18 \\
\hline TFSCfi & -100.00 & TFSCnfi & 12.38 & TFSCni & 81.38 \\
\hline TNSC $f i$ & 0.00 & TNSCnfi & 0.00 & TNSCni & 0.00 \\
\hline TFPCa & 294.92 & PCNFIa & -62.71 & TNPCa & 0.00 \\
\hline$T F P C b$ & 0.00 & PCNFIb & 0.00 & $T N P C b$ & 0.00 \\
\hline TFPCC & -100.00 & PCNFIC & 16.98 & $T N P C C$ & 65.70 \\
\hline TFPCd & -100.00 & PCNFId & 28.85 & TNPCd & 49.99 \\
\hline TFPCe & -100.00 & PCNFle & 15.25 & TNPCe & 53.29 \\
\hline TFPCf & -100.00 & PCNFIf & 40.94 & $T N P C f$ & 18.66 \\
\hline TotForeignProf & -100.01 & ProfNewFacility & 35.02 & TotNatProf & 115.37 \\
\hline TotProf & -32.72 & & & & \\
\hline
\end{tabular}

We clearly see in Table 3 that, apart from the income, costs, and profits of the Cuban plant being cancelled, the importance of increasing not only the income in the national plant $(+80.18 \%)$, but also its profits $(+115.37 \%)$, is stressed. Moreover, the Miami plant has increased income and profits (respectively $+24.10 \%$ and $+35.02 \%$ ), but to a lesser extent. The details of the output data can be found by clicking the following link: https://bit.ly/2ksVsCU

\section{CONCLUSIONS}

The internationalisation of manufacturing operations is a process that many companies have started in order to meet several objectives, such as cutting purchase and/or production costs, improving supply times and service levels by being located closer to customers, acquiring shares in expanding markets, and diversifying the international risk. However, this process has often been addressed without clearly set objectives, and without quantitatively analysing the current situation of the company and its surroundings suitably. In particular, as SMEs do not have sufficient tools and resources to study and develop business strategies, they often do not completely understand the chances and problems they will face. This paper has developed, and applied to a case study, a new MILP model for the internationalisation of manufacturing operations decision-making, quantitatively related to an analysis phase done with an NFI and GSND. Compared with the company's current and potential situation, the results have been satisfactory. With a suitable model with income and production/logistics costs, and with limitations to simulate possible scenarios, our results have shown how the company's resources are globally redistributed and relocated. The development of this model has been an opportunity to identify some production and logistics aspects that are sometimes missed - e.g., the importance of specialisation and technology when manufacturing a certain product type, which can lead dedicated companies to be created and developed that customers can contact to be supplied with raw materials; collaboration with companies to share resources [21]; the 
influence on production processes and, therefore, on the costs and profits of certain aspects - e.g., the company's culture and mentality, and those of the workers from the country where the company is located; and the circumstances of the location and the time period in question.

Thus we can state that the proposed MILP model acts as efficient quantitative support for the internationalisation of manufacturing operations decision-making, even with its limitations. We detected some improvement opportunities for this model, which could give way to future work lines: (i) implementing the model's results in tools, such as the TOPSIS method, to compare different alternatives with it by means of the weight assigned to evaluation criteria; (ii) considering the transport times (and not only the transport costs) of the equivalent units of raw material $r$ from suppliers - i.e., ttrrij - and the transport times of the equivalent units of finished product $u$ to reach customers - i.e., ttuujk; (iii) including pending orders, a more detailed calculation of the technological maintenance costs and more accurately calculating the plant's productivity; (iv) bearing in mind other types of costs: set or static, dynamic, and hidden [22]; (v) considering the efficiency index of production plants; (vi) incorporating uncertainty issues, such as uncertain and time-varying product demand; and (vii) considering economies of scale in transportation costs, among others. Finally, in this case study we have applied and solved the proposed model for a representative SME problem. Further work is aimed at scaling this model to larger problems in a supply chain context to assess its computational efficiency and identify infeasibility issues by also considering a sensibility analysis and different types of supply chain scenarios.

\section{ACKNOWLEDGMENT}

This work was supported by the Spanish Ministry of Science, Innovation and Universities project entitled 'Optimisation of zero-defects production technologies enabling supply chains 4.0 (CADS4.0)' (RTI2018101344-B-I00).

\section{REFERENCES}

[1] Stentoft, J., Olhager, J., Heikkilä, J. \& Thoms, L. 2016. Manufacturing backshoring: A systematic literature review. Operations Management Research, 9(3-4), 53-61.

[2] Johansson, M. \& Olhager, J. 2018. Manufacturing relocation through offshoring and backshoring: The case of Sweden. Journal of Manufacturing Technology Management, 29(4), 637-657.

[3] Leu, J.D. \& Huang, Y.T. 2011. E-logistics of global manufacturing enterprise: A case study. International Journal of Industrial Engineering: Theory, Applications and Practice, 18(7), 344-356.

[4] Leu, J.D. \& Huang, Y.T. 2011. Factory relocation of global manufacturing enterprises: A case study. International Journal of Industrial Engineering: Theory, Applications and Practice, 18(10), 524-535.

[5] Olhager, J. \& Feldmann, A. (2018). Distribution of manufacturing strategy decision-making in multi-plant networks. International Journal of Production Research, 56(1-2), 692-708.

[6] Monczka, R.M., Handfield, R.B., Guinipero, L.C. \& Patterson, J.L. 2009. Purchasing and supply chain management, $4^{\text {th }}$ ed. South-Western Cengage Learning, EEUU, Mason, $\mathrm{OH}$.

[7] De Meyer, A., Nakane, J., Miller, J. \& Ferdows, K. 1989. Flexibility: The next competitive battle the manufacturing futures survey. Strategic Management Journal, 10, 135-144.

[8] Tombido, L.L., Louw, L. \& Van Eeden, J. 2018. A systematic review of 3PLs' entry into reverse logistics. South African Journal of Industrial Engineering, 29 (3), 235-260.

[9] Rudberg, M. 2004. Linking competitive priorities and manufacturing networks: A manufacturing strategy perspective. International Journal of Manufacturing Technology and Management, 6(1-2), 55-80.

[10] Vereecke, A. \& Van Dierdonck, R. 2002. The strategic role of the plant: Testing Ferdow's model. International Journal of Operations and Production Management, 22(5), 492-514.

[11] Mediavilla, M. \& Errasti, A. 2010. Framework for assessing the current strategic plant role and deploying a roadmap for its upgrading: An empirical study within a global operations network. In Proceedings of APMS 2010 International Conference on Advances in Production Management Systems, Cernobbio, Italy.

[12] Sheffi, Y. 2007. Building a resilient organization. The Bridge: Linking Engineering and Society (Journal of the National Academy of Engineering), 37(1), 32-38.

[13] Martinez, S. 2013. Framework for configuring production and logistics networks of SMEs and SBUs within an internationalization process. PhD dissertation. Tecnun Universidad de Navarra.

[14] Tsiakis, P., Shah, N. \& Pantelides, C.C. 2001. Design of multi-echelon supply chain networks under demand uncertainty. Industrial and Engineering Chemistry Research, 40(16), 3585-3604.

[15] Georgiadis, M.C., Tsiakis, P., Longinidis, P. \& Sofioglou, M.K. 2011. Optimal design of supply chain networks under uncertain transient demand variations. Omega: The International Journal of Management Science, 39(3), 254-272.

[16] Meixell, M.J. \& Gargeya, V.B. 2005. Global supply chain design: A literature review and critique. Transportation Research Part E: Logistics and Transportation Review, 41(6), 531-550.

[17] Grillo, H., Mula, J., Martínez. S. \& Errasti, A. 2018. Key parameters for the analysis stage of internationalisation of operations. Brazilian Journal of Operations and Production Management, 15, $173-181$. 
[18] Armengol, A., Mula, J., Díaz-Madroñero, M. \& Pelkonen, J. 2021. An overview of the internationalisation of manufacturing operations: A review of literature. International Journal of Services Technology and Management. In press.

[19] Samut, P.K. \& Aktan, H.E. 2019. Integrating qualitative and quantitative factors in supplier selection and performance evaluation. South African Journal of Industrial Engineering, 30(2), 136-160.

[20] Ozfirat, P.M. 2020. A fuzzy event tree methodology modified to select and evaluate suppliers. South African Journal of Industrial Engineering, 31(1), 35-46.

[21] Poler, R., Hernández, J., Mula, J. \& Lario, F.C. 2008. Collaborative forecasting in networked manufacturing enterprises. Journal of Manufacturing Technology Management, 19(4), 514-528.

[22] Holweg, M., Reichhart, A. \& Hong, E. 2011. On risk and cost in global sourcing. International Journal of Production Economics, 131, 333-341. 